\title{
A STUDY OF HYBRID METHYL ESTER ON SINGLE CYLINDER DIESEL ENGINE
}

\author{
NIRAJ B. DOLE ${ }^{1}$, DR. RAHUL B BARJIBHE ${ }^{2} \&$ DR. SUPRIYA N BOBADE ${ }^{3}$ \\ ${ }^{1}$ Research Scholar at SSGBCOET Bhusawal, KBCNMU Jalgaon, India \\ ${ }^{2}$ Guide,Academic Dean at SSGBCOET Bhusawal, KBCNMU Jalgaon, India \\ ${ }^{3}$ Director, Indian biodiesel corporation, Baramati Maharashtra, India
}

\begin{abstract}
Consumption of fossil fuels to meet increasing demand of globalization is increased considerably resulting in depletion of fossil fuel reserves. Stringent environmental norms and increase in greenhouse gases emissions has forced researchers to search alternatives to fossil fuels. Biodiesel (Methyl Ester) is one of the alternatives that can be used as fuel in conventional diesel engine without any design modifications. Thispaper deals with synthesizing good quality of Methyl Ester from nahar and karanja seeds which is available cheaply in rural areas and grown in marginal lands. Different blends of nahar and karanja are prepared in order to investigate the properties of blends and if necessary ecofriendly additives are added with blends. Also, it deals with validation of properties of synthesized nahar and karanja Methyl ester according to ASTM 6751-96 standards.
\end{abstract}

KEYWORDS: Hybrid Methyl Ester, Nahar, Karanja

Received: Jun 08, 2020; Accepted: Jun 28, 2020; Published: Sep 16, 2020; Paper Id.: IJMPERDJUN20201270

\section{INTRODUCTION}

World's energy consumption has increased continuously since decade, because the world population is increasing and the economies of developing countries are expanding rapidly. Also, the source and supply of primary energy sources like coal, oil and natural gas seem to decrease to a critical point. The petroleum fuels are one of the major sources of energy are currently the dominant global source of $\mathrm{CO} 2$ emissions, greenhouse gases and global warming. The rise in petroleum prices and increase in environmental pollution jointly have necessary to find renewable alternatives to conventional petroleum fuels. Also, depletion of fossil fuels, vehicular population, increasing industrialization, growing energy demand, explosion of population, environmental pollution, emission norms, etc emphasize on the need for alternative fuels. The possible renewable energies are solar power, hydrogen, bioalcohol such as methanol, ethanol, butanol, propane, non-fossil methanol, non-fossil natural gas, emulsified fuels, biofuels mostly from non-edible seed oils, biodiesels. Recently, significant problems associated with fossil fuel like short supply, drastically increasing price, non-renewability, contamination of environment, adverse effect on bio systems compiles researcher to search for an alternative fuel, which promises a harmonious correlation with sustainable development, energy conservation, management, efficiency, and environmental preservation has become highly pronounced in the present context. The situation is very grave in developing countries like India which import $70 \%$ of the required fuel, spending $30 \%$ of his total foreign exchange on oil imports. In view of this, found and analyze many energy sources like CNG, LNG, LPG, ethanol, methanol, hydrogen, bio-diesel and many more. Among these alternative fuels, India is having significant scope for development of bio fuel. Diesel engines are widely used in transportation, power generation, marine application, agriculture vehicles etc. Moreover, transportation and agriculture sector depends on diesel fuel therefore, it is essential that alternatives to diesel fuels 
must be developed. In the view of these, vegetable oils like palm oil, karanja oil cotton seed oil, neem oil, are considered as alternative fuels to diesel which are promising alternative.

Biodiesel, an alternate fuel has attracted considerable attention during the past decade as a renewable, biodegradable and non-toxic fuel. Increasing uncertainty about global energy production and supply, environmental concerns due to the use of fossil fuels like petroleum products especially of diesel fuel has grown up significantly. A reduced cost than fossil fuel and produce biodiesel from waste fats and oils and another option for cost reduction is to reduce the cost of processing through optimizing the process variables that affect the yield and purity of biodiesel. In India, there are many trees bearing oil like ratanjot (jatrophacurcus), mahua (madhucaindica), pilu (salvodaraoleoids), nahor (mesuaferralina), kokam (garciniaindica), rubber seed (heveabrasilensis) and karanja (pongamiapinnata) etc. Among these species, which can yield oil as a source of energy in the form of biodiesel, Pongamiapinnata has been found to be one of the most suitable species due to its various favorable attributes like its hardy nature, high oil recovery etc. Also the use of naharoil (Mesuaferrea Linn) as a potential source of biodiesel.Nahar oil is a medium-sized to large evergreen tree with short runk, found in the Himalayas from Nepal east wards, in North-Eastern India,Deccan Peninsula and the Andaman Islands.

\section{LITERATURE REVIEW}

Availability and economic aspects are first considered when selecting biodiesel. The characteristics of engine performance are then considered, indicating the applicability of the biodiesel in engines. Brake power, brake torque, brake thermal efficiency (BTE), and brake specific fuel consumption (BSFC) are the performance indicators. Factors such as air-fuel mixture, fuel injection pressure, fuel spray pattern, and fuel properties affect performance. These parameters are tested against engine load or engine speed in the literature review. Engine performance characteristics of the reviewed biodiesel are discussed below.

Chavan S.B. et al. [1], observed that the Biodiesel can be produced from non edible oil like Jatrophacurcus, pongamiapinnata, Madhucaindica, Gossypiumarboreum, Simarouba glauca etc. and more. There is a best source as a raw material that is Undi oil (honne) oil for biodiesel production. As it is an evergreen tree and grows along the coastal area. Our study is focused on the collection of seeds and oil extraction then proceed for biodiesel production with molar ratio 8:1, $\mathrm{KOH}$ were $1.2 \mathrm{wt} \%$, temperature $65 \mathrm{oc}$, reaction time 90minutes were used and testing of parameters as per ASTM 6751 standards. The physical properties like acid value, density, Calorific value, Flash point, Fire point and Moisture, Viscosity shows of callophyllum methyl esters were $0.702,892 \mathrm{gm} / \mathrm{cc}, 37.18 \mathrm{MJ} / \mathrm{Kg}, 1760 \mathrm{c}, 1820 \mathrm{c}$ and $0.01 \%$. The physico-chemical parameters showed that Callophyllum may works as a sustainable feedstock for biodiesel production that is equivalent to fissile fuel as per ASTM 6751.Callophyllum oil exhibited good physicochemical properties and could be used as a biodiesel feedstock and as a industrial application. The way of reducing the biodiesel production costs is to use less expensive feedstock containing free fatty acids, such as non edible oils. With no competing food uses, this characteristic turns attention to undi oil linn which grows in costal area of in our country.

Jahirul M. I. et al, [2], observed that Seed processing, drying and oil extraction methods a significant impact on oil yields and the success of Beauty Leaf as future generation biodiesel feedscock. Drying the seed kernel to optimum moisture content was found to be crucial to the success of both mechanical extraction and hexane extraction. Kernels prepared with $15 \%$ moisture content provided the highest oil yields for both extraction methods. Mechanical extraction 
using the screw press is ineffective, with relatively low yields for a great deal of effort. Chemical extraction using hexane as a solvent was found to be very effective, however due to a limited supply of hexane and the lack of a hexane recovery system, it was not possible to take full advantage of the effectiveness of the method. Therefore it is recommended to use chemical oil extraction with hexane recovery system to reduce the production cost of Beauty Leaf biodiesel. Though less crucial than hexane recovery, it is noted that kernel preparation was the most time consuming element of the hexane extraction process experienced during the project. Therefore, a potential area for improvement or a possible future project would be to investigate streamlining/automating and up-scaling the kernel preparation process.

Bobade S.N. et al, [3],found that the jatropha oils can be used as a source of triglycerides in the manufacture of biodiesel by transesterification reaction. The biodiesel from refined vegetable oils meets the Indian requirements of high speed diesel oil. But the production of biodiesel from edible oil is currently much more expensive than diesel fuels due to relatively high cost of edible oil. There is a need to explore non edible oils as alternative feed stock for the production of biodiesel non-edible oil like jatropha. It is easily available in many parts of the world including India and it is cheaper compared to edible oils. Production of these oil seeds can be stepped up to use them for production of biodiesel. The production of biodiesel from this non edible oil provides numerous local, regional and national economic benefits. To develop biodiesel into an economically important option in India some innovations required for modification into the process to increase the yield of ester.

Bobade S.N. et al, [4], several processes of biodiesel fuel production have been developed, among which transesterification using alkali as a catalyst gives high level of conversion of triglycerides to their corresponding methyl ester in a short duration. This process has therefore been widely utilized for biodiesel fuel production in number of countries. In India, there are many trees bearing oil like ratanjot (jatrophacurcus), mahua (madhucaindica), pilu (salvodaraoleoids), nahor (mesuaferralina), kokam (garciniaindica), rubber seed (heveabrasilensis)andkaranja (pongamiapinnata) etc. Among these species, which can yield oil as a source of energy in the form of biodiesel, Pongamiapinnata has been found to be one of the most suitable species due to its various favorable attributes like its hardy nature, high oil recovery and quality of oil, etc. As the acid value of this oil is high so that we have to reduce it by the process of esterification follow by transesterification. The methyl ester produced by this way gives the good result. The study deals with transesterification of karanja oil which gives $907 \mathrm{ml}$ of karanja oil methyl ester (KOME) and 109ml of glycerol using methanol (13\%) and sodium hydroxide as a catalyst (1\%). The properties like density, viscosity, flash point, cloud point and pour point have been determined as per ASTM standards for accessing the fuel quality of KOME.

Dilipkumar bora et al[5] under a title of use of nahar oil methyl ester for CI engine studied that NOME with blends up to $30 \%$ in diesel gives almost comparable performance as that of neat diesel. Undesirable combustion symptoms of neat vegetable oils in diesel engine can be got rid of by way of transesterification. A blend (30\% by volume of NOME and $70 \%$ of neat diesel) can be effectively used in existing diesel engines without any engine hardware modification. However, effects on engine components including seal material and deposits on critical components with long term use need to be established as a part of future work on NOME based biodiesel.

Sanjay Basumatary [6] in his paper named as 'Non-Edible Oils of Assam as Potential Feedstocks for Biodiesel Production: A Review' said that Assam is one of the richest biodiversity zones in NE region of India. In the forests of North East India particularly in Assam, a large variety of non-edible oilseed bearing trees and shrub species are available for use as a biodiesel. Considering oil content, abundant availability and other fuel properties of the biodiesel that meet the 
properties prescribed in the biodiesel standards ASTM D6751 and EN 14214, the four species available in Assam (NE region of India) viz. yellow oleander (Thevetiaperuviana), koroch (Pongamiaglabra), terminalia (Terminaliabelerica) and nahar (Mesuaferrea) are considered as highly promising feedstocks for biodiesel industries. This species will be a sustainable resource replacing petroleum-derived diesel oil without significantly affecting the global food economy.

K. NanthaGopal [7] in his titled 'Effect of pongamia biodiesel on emission and combustion characteristics of DI compression ignition engine' The performance, emission and combustion characteristics of biodiesel derived from pongamia oil and its blends are compared with the conventional diesel fuel. Diesel engine can perform satisfactorily with pongamia oil methyl esters and their blends without any engine modifications.SFC increases with increase in percentage of biodiesel in the biodiesel blends because of the lower heating value of biodiesel.It is also observed that there is significant reduction in CO, UBHC and smoke emissions for all biodiesel blends when compared to diesel fuel. However, NOx emission of PME biodiesel is marginally higher than that of petroleum diesel.The combustion analysis showed that the biodiesel added to the conventional diesel fuel decreased the delay period and lowered the heat release rate of the premixed combustion. Thus, results indicate that pongamia oil methyl ester can be used as an alternative and environment friendly fuel for a diesel engine. However, detailed analysis of more blends will surely give an emphasis on the kind of bio-diesel that can be finally used in I.C. engines in the days to come in order to overcome the disadvantages of the petroleum diesel fuel that can be commercially developed as well.

Ramesh Ganugapenta [8]said in his paper 'performance analysis and characteristics of 4-stroke single cylinder diesel engine combine with karanja oil and coconut oil' that experiment have done successfully by using basic fuel of diesel. Later used mixed fuel of pongamia oil and coconut oil blend with diesel. In the blend fuel are different proportions of fuels is used. Leads to cause a efficiency improves slightly. Performance and emissions are equal to diesel engine without modification of engine parts. In the brake thermal efficiency have increases at the point of 1.4 of BP and decreases at point of $2.8 \mathrm{BP}$. The third reading of $\mathrm{D} 65 \% \mathrm{P} 25 \% \mathrm{C} 10 \%$ have a maximum thermal efficiency in increasing load nearly it can increase a 4-6\% of when compare with the diesel engine. In the brake specific fuel consumption less fuel consumption is D40\% P40\% C20\% by increasing of coconut oil fuel consumption is reduced. And minimum fuel consumption is D65\% $\mathrm{P} 25 \% \mathrm{C} 10 \%$. The above average of fuel consumption is $\mathrm{D} 55 \% \mathrm{P} 40 \% \mathrm{C} 15 \%$. as a result is obtain a increasing of coconut oil content some better less fuel consumption compare with the diesel. In the exhaust gas temperature have a minimum exhaust temperature is $\mathrm{D} 65 \% \mathrm{P} 25 \% \mathrm{C} 10 \%$. In the remaining particle ratio have a maximum amount of exhaust gas temperature. In the particle of P25\% are best suitable for exhaust temperature control. In the Pongamia oil have range of 25-30\% are the best suitable for all working process and less exhaust temperature. And additional to that coconut oil have a range oil of 10-20\% much suitable and additional to that coconut oil have a range oil of 10-20\% are best suitable for complete combustion.

S.V. Kale [9] discussed in his paper that the brake thermal efficiency obtained for B20 is closer to diesel fuel. A maximum brake thermal efficiency of $27.13 \%$ was achieved for B20 while for diesel it was $28.10 \%$ for the same power output. The Brake specific fuel consumption is slightly higher than diesel i.e. 3.2\% for B20 but closer to diesel among all the blends due to lower calorific value of biodiesel. Any further increase in percentage of bio diesel increases specific fuel consumption. The Mechanical Efficiency is decreased by $1.7 \%$ for B20 blend as compared to diesel value. While running the engine with biodiesel and its blends, emissions such as $\mathrm{CO}, \mathrm{HC}$ and smoke density were reduced by $72 \%, 10.8 \%$ and $10 \%$, as compared to diesel at full load. These reductions of emissions could be due to complete combustion of fuel. The 
NOx emission for B20 is increased by $6.2 \%$ at $4.25 \mathrm{~kW}$ load and $24 \%$ and at Full load compared to diesel, and as the concentration of pongamia increases the NOx emission is also increases. The combustion starts earlier for biodiesel and its blends than for diesel. The peak cylinder pressure of biodiesel (B100) is higher than that of diesel at No load. The peak cylinder pressure of diesel is higher than that of biodiesel and its blend at part load. The peak cylinder pressure of biodiesel (B40) blend is higher than that of diesel at full load. From all these observations, it could be concluded that the blends of pongamia with diesel up to $20 \%$ by volume could replace diesel for running the diesel engine with less emissions, without modifying the engine and without sacrificing the power output. This will thus help in controlling air pollution to a great extent.

Daming Huang et al [10] said in there paper 'Biodiesel: an Alternative to Conventional Fuel' that biodiesel have different advantages in terms of the type of biodiesel and its service condition, Biodiesel Conversion Technologies, Advantages of Emissions Produced by Biodiesel, Dynamic Property on Diesel Engine, Challenges of Biodiesel Industry Development, The Biodiesel Policy, The Prospect of the Application of Biodiesel. This paper reviews the history and recent developments of Biodiesel, including the different types of biodiesel, the characteristics, processing and economics of Biodiesel industry. The application of biodiesel in automobile industry, the challenges of biodiesel industry development and the biodiesel policy are discussed as well

K. Sureshkumara et al [11] in the paper 'Performance and exhaust emission characteristics of a CI engine fueled with Pongamiapinnata methyl ester (PPME) and its blends with diesel' discussed that present investigation was to analyze the usability of PPME as a replacement to diesel in an unmodified CI engine. It was found that blends of PPME and diesel could be successfully used with acceptable performance and better emissions than pure diesel up to a certain extent. From the experimental investigation, it is concluded that blends of PPME with diesel up to $40 \%$ by volume (B40) could replace the diesel for diesel engine applications for getting less emissions and better performance and will thus help in achieving energy economy, environmental protection and rural economic development. In the near future conventional fuels will be fully replaced by biodiesel and will provide a viable solution for the much threatening environmental pollution problems.

Brown J. R and et al [12] in their paper title as 'Optimization of Biodiesel Extraction Process from Beauty Leaf (Calophylluminophyllum) Oil Seed as A Second Generation Biodiesel Source' said that The Beauty Leaf tree (Calophylluminophyllum) is a potential source of non-edible vegetable oil for producing the biodiesel. Because of this seed having high ability to grow in a wide range of climate conditions, easy cultivation, high fruit production rate, and the high oil content in the seed. This plant naturally found in coastal areas of Queensland and the Northern Territory in Australia, and is also widespread in south-east Asia, India and Sri Lanka. Seed processing, drying and oil extraction methods a significant impact on oil yields and the success of Beauty Leaf as future generation biodiesel feedstock. Drying the seed kernel to optimum moisture content was found to be crucial to the success of both mechanical extraction and hexane extraction. Kernels prepared with $15 \%$ moisture content provided the highest oil yields for both extraction methods Mechanical extraction using the screw press is ineffective, with relatively low yields for a great deal of effort. Chemical extraction using hexane as a solvent was found to be very effective, however due to a limited supply of hexane and the lack of a hexane recovery system; it was not possible to take full advantage of the effectiveness of the method. Therefore it is recommended to use chemical oil extraction with hexane recovery system to reduce the production cost of Beauty Leaf biodiesel. Though less crucial than hexane recovery, it is noted that kernel preparation was the most time consuming element of the hexane extraction process experienced during the project. Therefore, a potential area for improvement or a 
possible future project would be to investigate automating and up-scaling the kernel preparation process.

Rahul KrishnajiBawane [13] told that Increase in energy demand and it is necessary for the development of renewable energy sources. Experimental work is conducted to obtain the operating and emission characteristics of Undi Oil Biodiesel on Variable Compression Ratio (VCR) engine run on various blends of biodiesel, compression ratios and load conditions. The study and evaluate using biodiesel as an alternative fuel in VCR engine. 1. Biodiesel and its blends results in slightly decreased brake thermal efficiency as compared to diesel over the entire range of compression ratio. 2. BSFC for biodiesel and its blends are higher than that of diesel. 3. Exhaust Gas Temperature for the biodiesel is lower at all conditions as compared to diesel. 4. The CO emissions are higher at lower compression ratio, and decreased at higher compression ratio. 5. The $\mathrm{CO}$ emissions for biodiesel and its blends are higher, compared to diesel over the entire range of fuel blends. 6. The biodiesel and its blends emit lower percentage of $\mathrm{CO} 2$ as compared to diesel at higher compression ratio. 7. The $\mathrm{HC}$ emission decreases with increase in compression ratio for the entire range of fuels, and for biodiesel and its blend it is higher than diesel. 8. The NOx emission for entire range of fuel is higher at low compression ratio this is due to highest temperature is observed at this compression ratio. 9. The $\mathrm{O} 2$ emission increases continuously with increases in compression ratio. 10. Biodiesel and its blends shown higher $\mathrm{O} 2$ emission as compared to diesel. the above conclusions, it is proved that the biodiesel could be used as an alternative fuel in VCR engine without any engine modifications.

S. A. Ransing [14] said that Fossil fuel sources and emissions are continuously decreasing worldwide. This gives researchers an alternative discovery Fuel for internal combustion engine. Biodiesel (fatty acid methyl / ethyl ester) Returns an optimistic option, obtained through transesterification from triglycerides Renewable, biodegradable fuel. The biodiesel used here is the undi oil. undi oil is mixed Different quantities of diesel The mixing properties have been tested by ASTM D6751 Standard. The test on single cylinder has been made four strokes continuously Diesel engines using pure diesel, 10\%, 20\%, 30\%, 40\% and 100\% mix. Machine The engine has been certified using the GT-Power Simulation software. Diesel engines emit an particular matter (PM) and oxides of nitrogen (NOx). They also emit small percentage of hydrocarbon ( $\mathrm{HC}$ ) and carbon monoxide (CO). It is seen that use of biodiesel as an alternate fuel in $\mathrm{CI}$ engine reduces $\mathrm{CO}$, HC and smoke emissions but increases NOx emission due to higher oxygen content of biodiesel as compared to diesel. Performance curves such as brake thermal efficiency (BTE), brake specific fuel consumption (BSFC) have been plotted for pure diesel and blends. Performance results for B20 (20\% undi oil and 80\% diesel) follow closely to that of pure diesel. The aim of this project is to experimentally investigate the effect of biodiesel and its blends on CI engine performance. Raw undi oil contain more fatty acids (FFA). When oil is removed through the transesterification process, this reduces in FFA and reduces viscosity of oil Use oil as the oil and its mixture as an alternative mixture below has been studied. It seen that undi biodiesel can be used Diesel engine without any improvement. The mixture like B10, B20, B30, B40 and B100 are used Single-cylinder diesel engine and performance parameters are calculated. The BTE and BSFC graphs show that, among all blends B20 blend follow closely to that of pure diesel. From experimental results, B20 blend shows 2.51\% variation in BTE and $7.17 \%$ variation in BSFC at maximum power when compared with that of pure diesel. The experimental results for BTE and BSFC of pure diesel and B20 blend vary within 10\% when compared with that of simulation results. Simulation results of emission show that NOx emission increases and HC emission decreases with increase in percentage of biodiesel in blend.

David K. Chirchir [15] said that Due to fossil fuel loss, there is a need to find out Durable alternate fuel to meet rising energy demand Reduced global fuel supply, environmental problems, Growth and expected increase in fossil fuel 
prices Population, especially with a fast growing economy like China And India clearly shows the need for more sustainable energy Source fossil fuels are also known as environmental degradation So searching for alternative sources is a feasible option. Related Diesel engines, particles and nitrogen rules Oxide emissions have been strengthened to reduce adverse health Effects and greenhouse emissions to reduce weather As a change, there may be research on alternative fuels There is an option for fossil fuels in combustion engines under diesel Essential waste is not able to escape the pending oil Restaurants can work as energy alternatives. Diesel Engines are used extensively because of their high power output, fuel Economy and Lower Hydrocarbons (HC) and Carbon Monoxide (CO) Emissions from gasoline engines However, particular matter (PM), nitrogen oxides (NOx), sulfur oxide (SOX), polycyclic aromatic hydrocarbons (PAHs) and diesel Engineers are always very worrisome. Use of straight vegetable oils in pure form is possible but not preferable because high viscosity and low volatility affecting the atomization and spray pattern of fuel leading to incomplete combustion, severe carbon deposits, injector choking and piston ring sticking. Transesterification is one of the methods for reducing viscosity. Biodiesel as alternative fuel Diesel engines can reduce carbon monoxide, carbon dioxide, Hydrocarbons, particulate matter and sulphur oxide emissions with slightly increased Brake Specific Fuel Consumption (BSFC) but Increases nitrogen oxide emissions. To reduce NOx emissions Exhaust, it is necessary to keep the combustion temperature under control. Exhaust gas recirculation is the effective technique for nitrogen oxides (NOx) reduction. Using biodiesel reduces fossil fuel consumption.

Saravanan D and et al [16] said that in case of reducing the emissions and improve the performance of the engine. In CI engine, the combustion is heterogeneous and the time allowed for mixing of fuel with air in particular oxygen is very less so there is partial mixing of the fuel which makes the mixture rich at certain places leading to the formation of particulate matter and very leaner at some places leading to formation of NOx. Blending DEE with diesel and its usage in conventional diesel engine increases the brake thermal efficiency and reduces the BSFC. The NOx emissions are reduced and there is a an increase in the $\mathrm{CO}$ and $\mathrm{HC}$ emission this can be avoided if optimum DEE and Diesel fuel blending ratio is used without making the fuel mixture to be too lean. The high latent heat of evaporation of DEE counter acts the cetane benefit which increases the $\mathrm{HC}$ emission.

JagannathHirkude and et al [17] said in the paper that In this study, the effect of input parameters (CR, Load and Blend) on the improvement in performance and reduction of exhaust emissions were investigated on a single cylinder diesel engine. The conclusions of this work based on the results of this study are as follows: Compression ratio, biodoesel blend and load influences performance and emission characteristics of the engine. Increase in compression ratio increases brake thermal efficiencies for all blends. The brake specific fuel consumption increases with increase in WFOME in the blends. It was observed that exhaust gas temperature increased with increase in WFOME in the blends. With increase in CR reduction in emission parameters like $\mathrm{CO}$ and PM were observed. Further reduction in CO and PM was observed with increase in WFOME blend in diesel. But NOx emission increases with increase in CR because of high temperature level at higher CR.Desirability approach of RSM found extremely efficient optimization technique to optimize input parameters. Optimal input parameters for performance were observed at B0 and CR of 15.8. While Minimum level of exhaust emission were observed at B57 and CR of 14.5. It can be concluded from this paper that B30 at $3 \mathrm{~kW}$ loading condition could be could compromise to run the engine (of CR -16.5) with WFOME.Validation of test result showed that developed models were quite accurate and in good agreement. Further effect of some other important parameters like injection pressure and injection timing along with compression ratio should be analyzed. 
Wail M. Adailehand et al [18] told that the characteristics of Biodiesel are close to diesel fuels, and therefore Biodiesel becomes a strong source to replace the diesel fuels. The conversion of triglycerides into methyl or ethyl esters through the transesterification process, reduces the molecular weight to one-third that of the triglyceride and also reduces the viscosity by a factor of about eight and increases the volatility Marginally. Biodiesel has viscosity close to diesel fuels. These esters contain 10-11\% oxygen by weight, which may encourage more combustion than hydrocarbon-based diesel fuels in an engine. The cetane number of Biodiesel is around 50. The use of tertiary fatty amines and amides can be effective in enhancing the ignition quality of the finished diesel fuel without having any negative effect on its cold flow properties. Since the volatility increases marginally, the starting problem persists in cold conditions.Biodiesel is considered clean fuel it has no sulphur no aromatics and has about $10 \%$ built in oxygen, which helps it to burn fully its higher cetane number improves the ignition quality even when blended in the petroleum diesel. It is a general property of hydrocarbons that the auto-ignition temperature is higher for more volatile hydrocarbons. Therefore, the less volatile middle distillate fractions of crude oil boiling in the range of $250-370{ }^{\circ} \mathrm{C}$ are suitable as diesel fuels.

A.M. Liaquat [19] said that the engine performance and emissions of using blend fuels such as JB5, JB10 and J5W5 were investigated and compared with diesel fuel: Engine torque and brake power for blend fuels were decreased when compared to diesel fuel, mainly due to their respective lower heating values. However, J5W5 showed lower reduction compared to JB10. The bsfc values for blend fuels were higher than that of DF due to lower heating values and higher densities. It is also noted that at some lower engine speeds, the bsfc values for blend fuels were found lower than that of DF because of the improved combustion due to the inherently oxygen containing. In case of engine exhaust gas emissions, reduction in $\mathrm{HC}, \mathrm{CO}$ and $\mathrm{CO} 2$ were found for JB5, JB10 and J5W5 when compared to DF at both engine operating conditions. Whereas, NOx emission for all blend fuels was increased as compared to DF. However, J5W5 was found to be comparable with JB10 and produced better results except NOx. In comparison with the diesel fuel, blend fuels produced lower sound levels due to many factors including increase in oxygen content, reduction in the ignition delay, higher viscosity, lubricity etc. However, among all the blend fuels J5W5 produced the lowest level of sound.

G. Najafi [20]in the paper 'Diesel engine combustion characteristics using nano-particles in biodieseldiesel blends' said that Adding Ag and CNT nano-particles in biodiesel-diesel blended fuel can improve the CI engine combustion and performance parameters. It can be found that the heat release rate of thedi $\square$ usion combustion phase is higher for biodiesel and biodiesel with nano additives when compared with that of neat diesel fuel due to the higher oxygen content of the blended fuels that have improved the di $\square$ usion combustion phase and decreased the combustion duration. Peak pressure was increased up to $15.38 \%$ in BD+CNT120 (Biodiesel+120ppm Carbon Nano Tubes nano additive). The innovated fuel blend also increases peak pressure rise rate and heat release rate by up to $23.33 \%$ and $28 \%$ respectively. Ignition delay was decreased $8.98 \%$ in BD+CNT120 compared to neat diesel fuel. The innovated fuel blend also increased engine performances i.e., power and torque by and decreased specific fuel consumption compared to neat diesel fuel. $\mathrm{CO}$ and $\mathrm{HC}$ were reduced and $\mathrm{CO} 2 \& \mathrm{NO} \mathrm{x}$ increased compared to neat diesel fuel.

Prabhu L and et al [21]said in the paper 'Performance and Emission Characteristics of a Diesel Engine Using Nano Particle as Additive with Biodiesel' that The performance and emission characteristics of neat diesel and dieselbiodiesel blends with the addition of titanium oxide nanoparticles are investigated to evaluate the emission reduction potential on the diesel engine. The following conclusions were drawn from the experimental results. The brake thermal efficiency of neat diesel is higher than diesel-biodiesel blends at all the loads and a small improvement is observed with the 
addition of titanium oxide with $20 \%$ diesel-biodiesel blends without nano particle addition. The brake thermal efficiency is increased by $32 \%$ for B20 with addition nano particle compared to $20 \%$ diesel-biodiesel blends without nano particle addition at full load. The BSFC is higher for diesel-biodiesel blend compared with diesel. The BSFC is decreased by $10 \%$ for B20 with nano particle compared with $20 \%$ diesel biodiesel blends without nano particle addition. The carbon monoxide and hydrocarbon emissions decreased with the use of nanoparticles in diesel-biodiesel blends compared and B20 and neat diesel. The CO and HC emissions are decreased by $20 \%$ and $17.5 \%$ respectively for B20 with nano particle additives at full load compared with $20 \%$ diesel-biodiesel blends without nano particle addition. The NO emissions are increased about $5 \%$ for $20 \%$ diesel-biodiesel blends with nano particle compared with biodiesel blends without nanoparticle addition. The smoke emission decreased by $27 \%$ for $20 \%$ diesel-biodiesel blends with nano particle compared with biodiesel blends without nano particle addition. On the whole, it is concluded that the addition of titanium oxide nano particle can be used as additive with biodiesel blends for improvement of performance and reduction in emissions except marginal increase in NO emissions.

M. Ghafoori [22]said that Engine test results showed that maximum power was $63 \mathrm{~kW}$ at $900 \mathrm{rpm}$ for D80B20 (80\%vol. diesel+20\%vol. biodiesel) blended fuel that contains 30 ppm carbon nanotubes. The results show that engine's power with D80B20 that contains 30 ppm nanoparticles compared to diesel fuel increases by about 17 percent. Maximum torque was $350 \mathrm{Nm}$ for D80B20 blended fuel that contains $30 \mathrm{ppm}$ carbon nano-tubes. The results show that engine's torque with D80B20 that contains 30 ppm nano-particles compared to diesel fuel increases by about 18 percent. Maximum reduction in fuel consumption depends on B20D80 with 20 ppm carbon nano tube. Increase of nano-particles to more than $10 \mathrm{ppm}$ causes a reduction in fuel consumption. So, the reduction of fuel consumption was about $10 \%, 35 \%, 55 \%$ and $34 \%$ for the fuel that contains 10,15, 20 and $30 \mathrm{ppm}$ nano particles respectively. The sfc (specific fuel consumption) at different engine speeds for B20D80 blended fuel with 10, 15, 20 and 30 ppm of nano particles was decreased by 10\%, 39\%, 38.5\%, and $35 \%$ respectively in comparison to diesel fuel. This result indicates that adding nanoparticles to biodiesel-diesel blended fuel can significantly reduce fuel consumption and specific fuel consumption due to the fact that the Carbon Nano tubes accelerate the combustion and the combined effect of these nanoparticles additive leads to the improvement in fuel economy, thereby increasing the brake thermal efficiency. The HC concentration at different engine speeds and the B20D80 blended fuel with $2.5,5,7.5,10,15,20$ and 30 ppm of nano particles was decreased by 12\%, 17\%, 19\%, 13\%, 14\%, 20\% and $22 \%$ respectively in comparison to diesel fuel. This result indicates that adding nanoparticles to biodiesel-diesel blended fuel can significantly reduce HC emission. The addition of Nano-particles and Carbon Nano tubes enhances the combustion and cause for the hydro carbon emission reduction. This could be due to the intensive secondary atomization and significant fuel distribution in the presence of CNT in the combustion chamber, thereby causing the hydrocarbon oxidation. The CO concentrations at different engine speeds using B20D80 with 2.5, 5, 7.5, 10, 15, 20 and 30 ppm of nano particles was decreased by $23 \%, 9 \%, 7 \%, 8 \%, 2 \%, 10 \%$ and $14 \%$, respectively in comparison to diesel fuel. The reduction in $\mathrm{CO}$ concentration using blended fuels is due to the fact that biodiesel has less carbon than diesel. The CO2 concentration in the exhaust gas emission at $1000 \mathrm{rpm}$ for B20D80 fuel with $15 \mathrm{ppm}$ nanoparticles increased 23\% (maximum). This phenomenon proves that adding nanoparticles to biodiesel-diesel blended fuel improves combustion. The presence of the CNT nanoparticle changes the reaction patterns and heat transfer rate, which increases the $\mathrm{CO} 2$ percentage in the emission.It is recommended to use CNT and other nanoparticles in diesel engines with dieselbiodiesel blended fuels to enhance the performance and reduce the emissions of engine.

Y.M. TAN [23] said in his paper that nanodiesel could be efficiently utilized as blended fuel in diesel engine. The 
produced nanodiesel was blended with biodiesel and diesel fuels in different concentrations and the CI engine performance and emission parameters were evaluated with these new blended fuels. Adding nano particles in diesel fuel can improve engine performance and reduce $\mathrm{CO}$ and $\mathrm{HC}$ emissions. But it can cause an increase in CO2 and NOX emissions. SVM can be employed to predict the engine performance and exhaust emissions. SVM can be employed to predict the engine performance and exhaust emissions. But there is a need for finding the optimum values of its parameters. The SVM results were very good, R values in this model are very close to one, while root mean square error (RMSE) was found to be very low. The results showed that SVM predicted the engine performance and exhaust emissions with correlation coefficient (R) and accuracy in the range of $0.66-1$ and $65-99.5 \%$. The results demonstrate that SVM is capable of predicting the CI engine performance and emissions. Analysis of the experimental data by the SVM method revealed that there is a good correlation between the SVM predicted results and the experimental data. Therefore, SVM proved to be a useful tool for correlation and simulation of engine parameters.

ArunBalakrishnan and et al [24] in their paper discussed that the key parameters that influence NOx emissions in diesel engines fuelled with biodiesel blends were identified and broadly classified as fuel chemistry effects, engine control effects and fluid dynamics effects. In most engine studies, with a few exceptions, biodiesel or biodiesel blends resulted in increased NOx emission compared to baseline diesel; however, the change in NOx emission for blends varied nonmonotonically with the biodiesel content due to a complex dependence of NOx formation on various factors at various conditions. The relative significance and extent of influence of various physico-chemical factors reviewed in this article differ with engine type, cycle and operating conditions. Hence, a holistic approach is needed to investigate the biodiesel blending effect on NOx emission by discerning the influential factors and then integrating the appropriate individual findings along with the corresponding coupled effects of thermo-fluid-chemical interactions for the particular combustion environment.

Vivek W and et al [25] said that in their paper 'Effect of nanofluid additives on performances and emissions of emulsified diesel and biodiesel fueled stationary CI engine: A comprehensive review' that According to analysis of above research papers, it can be concluded that broad range of nano fluid additives can be used as additives in diesel and biodiesel due to increased surface area to volume ratio, increased in catalytic activity in nano size metal oxides and metals. Nano fluid increases better combustion due micro explosion phenomenon. Following conclusions can be drawn from the analysis of above literatures It can be concluded that addition of nano particles improves the calorific value and cetane number of diesel and biodiesel fuel. However viscosity, flash point and density of fuel are slightly increased. It is evident from literatures that nano fluid enhances combustion of fuel due to improvement in heat transfer, catalytic activity, air fuel mixing rate. The results showed that brake specific consumption decreases with dosing of nano particles additive due to enhanced calorific value, catalytic oxidation and complete combustion of fuel. It is evident from the literatures that the higher brake thermal efficiency was obtained using nano fluid additives by promoting complete combustion. The results showed that increasing dosing level of nano fluid additives increases the brake thermal efficiency. Most of the additives showed reduction in NOx due to higher cetane number and reduction in HC due to higher evaporation rate and catalytic oxidation. Lower smoke emission was observed by most of the authors due to higher evaporation rate, reduced ignition delay. Some authors observed increase in $\mathrm{CO}$ emission and some authors observed decrease in $\mathrm{CO}$ emission due to improved ignition characteristics with nano fluid additives. At higher concentration of nano fluid additives, the higher $\mathrm{CO}$ emission was observed. It can be concluded from few studies that increase in cylinder pressure and heat release rate using nano particles was obtained. Also, higher evaporation rate was obtained in researches. 


\section{CONCLUSIONS}

With the progress of literature review I come to the conclusion of importance and use of biodiesel. Various authors study the effect of use of different types of methyl ester. Parameters like compression ratio, load, and proportion of blends are studied by them. By testing of various biofuels we get the information regarding their emissions characteristics like co,co2,hc content and performance parameters like brake thermal efficiency, break specific fuel consumption, heat balance sheet etc. So finally by studying the literature review I come to the conclusion that use of hybrid methyl ester can the better alternative fuel to the diesel in future.

\section{REFERENCES}

1. Chavan S.B., Kumbhar R.R. and Deshmukh R.B., "CallophyllumInophyllum Linn ("honne") Oil, A source for Biodiesel Production" in Research Journal of Chemical Sciences, November 2013, Vol. 3(11), pp. 24-31.

2. Jahirul M.I, Brown J.R, Senadeera W, Ashwath N, Ashwath N, Lating C, Leski-Taylor J, Rahul M.G., "Optimisation of bio oil extraction process from beauty leaf (calophylluminophyllum) oil seed as a second generation biodiesel source" in 5th BSME international conference on thermal engg, 2013 , vol I, pp 619-624.

3. Bobade S.N., Kumbhar R.R. and Khyade V.B., "Preparation of Methyl Ester (Biodiesel) from JatrophaCurcas Linn Oil” in Research Journal of Agriculture and Forestry Sciences, March (2013), Vol. 1(2), pp.12-19.

4. Bobade S.N. and Khyade V.B., "Preparation of Methyl Ester (Biodiesel) from Karanja (PongamiaPinnata) Oil" in Research Journal of Chemical Sciences, August (2012), Vol. 2(8), pp. 43-50.

5. NZIU, P., \& MASU, L. OFFSETTING OF CIRCULAR CROSS BORE EFFECTS ON ELASTIC PRESSURIZED THICK CYLINDERS.

6. Dilip Kumar Bora and RupanjaliNath, “Use Of Nahar Oil Methyl Ester (NOME) In A CI Engines” Journal of Scientific \& Industrial Research Vol. 66, March 2007, pp.256-258.

7. Sanjay Basumatary, "Non-Edible Oils of Assam as Potential Feed stocks for Biodiesel Production” in Research Journal of Chemical, Biological and Physical Sciences, November 2012 - January 2013, Vol. 3, pp. 1,551-558 e- ISSN: pp. 2249 -1929.

8. K. NanthaGopal, R. ThundilKarupparaj, "Effect of pongamia biodiesel on emission and combustion characteristics of DI compression ignition engine” in Research Ain Shams Engineering Journal (2015) 6, 297-305.

9. Ramesh Ganugapenta, K.V.N.V.N Rao, B.R. Satheesh Raja, M. Dora Babu, "Performance Analysis And Characteristics Of 4-Stroke Single Cylinder Diesel Engine Combine With Karanja Oil And Coconut Oil” ISSN pp. 2393-8374, Volume-5, Issue-2, 2018.

10. S.V. Kale," Performance Characteristics Of Di -Ci Engine Using Pongamia Biodiesel- Diesel Blend As Fuel” In Research International Journal Of Advanced Engineering Research And Studies E-Issn2249-8974.

11. Krishnaveni, J., Sowmya, G., \&Sudhakar, U. (2014). Thermal Analysis Of Cylinder Head By Using Finite Element Analysis. International Journal of Mechanical Engineering (IJME) ISSN (P), 2319, 2240.

12. Daming Huang, Haining Zhou, Lin Lin, “Biodiesel: An Alternative to Conventional Fuel” Procedia Engineering 16 (2012) 1874 - 1885.

13. K. Sureshkumara, R. Velrajb, R. Ganesana, "Performance And Exhaust Emission Characteristics Of A Ci Engine Fueled With PongamiaPinnata Methyl Ester (PPME) and Its Blends With Diesel” A Paper of Renewable Energy 33 (2008) $2294-2302$.

14. Jahirul M. I., Brown J. R., Senadeera W., Ashwanath N., Laing C., Leski Taylor J., Rasul M. G., "Optimization of Bio-Oil Extraction Process From Beauty Leaf (ColophyllumInophyllum) Oil Seend As a Second Generation Biodiesel Source” A Research paper Procedia Engineering 56 ( 2013$)$ pp. $619-624$.

15. Rahul KrishnajiBawane, SV Chanapattana, Abhay A Pawar, "Performance Test Of CI Engine Fueled With Undi Oil Biodiesel Under Variation In Blend Proportion, Compression Ratio \& Engine Load” International Journal Of Science, Engineering And Technology Research (IJSETR), Volume 3, Issue 8, August 2014. 
16. S. A. Ransing, m.H. Attal, "Experimental Study on Diesel Engine Performance Using Undi Oil Biodiesel and Its Blends" in Research International Engineering Research Journal (IERJ) Special Issue 2 pp. 4761-4765, 2015, IAAN pp.2395-1621, 2015.

17. LATHASREE, P., \& YUGENDHER, M. DESIGN AND OPTIMIZATION OF AN ISOGRID COMPOSITE CYLINDER USING FEA.

18. David K. Chirchir, Robert Kiplimo And Hiram Ndiritu," Review of The Performance and Exhaust Emissions Characteristic Of a Diesel Engine Running on Waste Vegetable Biodiesel Oil" in Research Paper Proceedings Of 2013 Mechanical Engineering Conference On Sustainable Research And Innovation, Volume 5, 24th - 26th April 2013.

19. Umesh, K. S., Pravin, V. K., \&Rajagopal, K. (2014). Experimental Investigation and CFD Analysis of Multi-Cylinder Four Stroke SI Engine Exhaust Manifold for Optimal Geometry to Reduce Back Pressure and to Improve Fuel Efficiency. International Journal of Automobile Engineering Research and Development, 4, 13, 20.

20. Saravanan D., Vijayakumar T. And Thamaraikannan M., "Experimental Analysis Of Combustion And Emissions Characteristics Of CI Engine Powered With Diethyl Ether Blended Diesel As Fuel” Research Journal Of Engineering Sciences ISSN 2278 - 9472 Vol. 1(4), pp. 41-47, October (2012).

21. JagannathHirkude,*, AtulPadalkar, ShafeeShaikh, AvilVeigas, "Effect of Compression Ratio on Performance of CI Engine Fuelled With Biodiesel From Waste Fried Oil Using Response Surface Methodology International Journal of Energy Engineering 2013, 3(5): pp. 227-233.

22. Wail M. Adaileh1 and Khaled S. AIQdah, "Performance of Diesel Engine Fuelled by a Biodiesel Extracted From A Waste Cocking Oil" in Research Paper Energy Procedia 18 (2012) 1317 - 1334, pp.1017-1034.

23. A.M. Liaquat, H.H. Masjuki, M.A. Kalam, M. Varman, M.A. Hazrat, M. Shahabuddin, M. Mofijur, "Application of blend fuels in a diesel engine" in 2nd International Conference on Advances in Energy Engineering (ICAEE 2011) Energy Procedia 14 (2012) 1124 - 1133.

24. G. Najafi, "Diesel Engine Combustion Characteristics Using Nano-Particles In Biodiesel Diesel Blends" in Research of Fuel 212 (2018) pp. $668-678$.

25. Prabhu L, S. Satish Kumar, S. Ramachandran, Dr.K.Rajan, "Performance and Emission Characteristics of a Diesel Engine Using Nano Particle as Additive with Biodiesel” in Research International Journal of Applied Engineering Research ISSN 0973-4562 Volume 9, Number 23 (2014) pp. 18759-18770.

26. M. Ghafoori, B. Ghobadian, G. Najafi, M. Layeghi, A. Rashidi and R. Mamat, "Effect of nano-particles on the performance and emission of a diesel engine using biodiesel-diesel blend" in research International Journal of Automotive and Mechanical Engineering (IJAME) ISSN: pp. 2229-8649 (Print); ISSN: pp. 2180-1606.

27. Umesh, K. S., Pravin, V. K., \&Rajagopal, K. (2013). Experimental Analysis of Optimal Geometry for Exhaust Manifold of Multi-cylinder SI Engine for Optimum Performance. International Journal of Automobile Engineering Research and Development, 3(4), 11-12.

28. Y.M. Tan, "Study Performance of Diesel Engine With Nano Particle Addative Diesel Blended Fuel" In Books Of Mechanical System Design, 27 April 2016

29. ArunBalakrishnan, Ramkumar N. Parthasarathy, Subramanyam R. Gollahalli, “A Review On The Effects of Biodiesel Blends on Compression Ignition Engine Nox Emissions” In Research Journal Of Energy And Environmental Sustainability, 1 (2016) pp. 67-76.

30. VivekW.Khond V. M. Kriplani, "Effect of nano fluid Additives on performances and emissions of Emulsified Diesel and biodiesel fueled stationary CI Engine: A comprehensive review” in Research of Renewable and Sustainable Energy Reviews 59(2016) pp. 1338-1348. 